\title{
X-Ray Absorption Spectroscopy Analysis of Lead Species Adsorbed on Various Oxides from High pH Solution
}

\section{Takanori Miyake1, Tetsuo Honma², Hiroshi Arimatsu', Hiroto Fukunishi' ${ }^{1}$, Huimin Liu1,

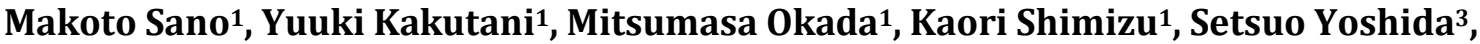 Kazumasa Suetsugu ${ }^{3}$}

\author{
${ }^{1}$ Faculty of Urban and Environmental Engineering, Kansai University, Suita, Osaka, Japan \\ ${ }^{2}$ Japan Synchrotron Radiation Institute (JASRI), Sayo-cho, Hyogo, Japan \\ ${ }^{3}$ TOSOH Corporation, Shunan, Yamaguchi, Japan \\ Email: tmiyake@kansai-u.ac.jp
}

How to cite this paper: Miyake, T., Honma, T., Arimatsu, H., Fukunishi, H., Liu, H., Sano, M., Kakutani, Y., Okada, M., Shimizu, K., Yoshida, S. and Suetsugu, K. (2020) X-Ray Absorption Spectroscopy Analysis of Lead Species Adsorbed on Various Oxides from High pH Solution. Journal of Environmental Protection, 11, 807-820. https://doi.org/10.4236/jep.2020.1110050

Received: August 27, 2020

Accepted: October 9, 2020

Published: October 12, 2020

Copyright $\odot 2020$ by author(s) and Scientific Research Publishing Inc. This work is licensed under the Creative Commons Attribution International License (CC BY 4.0).

http://creativecommons.org/licenses/by/4.0/

\section{(c) (i) Open Access}

\begin{abstract}
Lead dissolved in water must be removed in order not to cause diseases, especially from high $\mathrm{pH}$ aqueous solution. Various oxides having high specific surface area are often applied to remove lead in water media. To improve removal ability for lead species, it is necessary to understand the adsorbed structure of lead species on oxides. At first, the adsorption behavior of lead from high $\mathrm{pH}$ solution in the presence of $\mathrm{Ca}^{2+}$ and $\mathrm{Na}^{+}$was compared. Lead and calcium species were adsorbed up to the monolayer, and the adsorption isotherm was analyzed as Langmuir-type adsorption. In the presence of $\mathrm{Ca}^{2+}$, the amount of removed lead was reduced. To clarify this influence of $\mathrm{Ca}^{2+}$, $\mathrm{X}$-ray absorption spectroscopy was adopted. It was for the first time revealed that lead species at $\mathrm{pH}>12$ and $\mathrm{pH}<10.5$ differed, and that lead species adsorbed on various oxides had a similar structure.
\end{abstract}

\section{Keywords}

X-Ray Absorption Spectroscopy, Water Purification, Lead Removal, Manganese Oxide, Adsorption

\section{Introduction}

In our daily life, a large amount of wastes such as domestic garbage, used plastics, and papers, are disposed. These wastes, called municipal wastes, are incinerated, which leave ash to be withdrawn from the bottom of the incinerator and fly ash to be collected by the electric dust collector. The fly ash contains signifi- 
cant amounts of poisonous elements such as lead and cadmium, and causes problems when buried [1] [2] [3] [4]. This is because calcium hydroxide solution is sprayed onto the fly ash to neutralize hydrogen chloride and sulfur oxides. Then, when the fly ash is buried and rain reaches the buried ash, the $\mathrm{pH}$ of the eluent can reach as high as $\mathrm{pH} 12$, which leads to dissolution of lead. To prevent dissolution of lead, the fly ash is solidified into cement or is chemically treated using chelate compounds [5]. The former method necessitates a special facility and is costly. In the latter method, chelate compounds are expensive and gradually degrade after months, releasing lead. Thus, a better and preferably permanent treatment for lead from the fly ash is needed.

There have been many reports to make heavy metals immobilize with $\mathrm{SiO}_{2}$ and $\mathrm{Al}_{2} \mathrm{O}_{3}$ [6] [7] [8] [9] [10]. Studies on adsorption using mesoporous materials have also been reported [11]-[22]. However, these methods cannot be adopted for lead removal because $\mathrm{SiO}_{2}, \mathrm{Al}_{2} \mathrm{O}_{3}$, and most of the mesoporous materials dissolve into high $\mathrm{pH}$ aqueous solution. Mesoporous manganese oxide having a large surface area has been reported [23] [24] [25]. Papers dealing with lead removal using manganese oxide are reported; however, no papers adopted $\mathrm{pH}$ higher than neutral to the best of our knowledge. Manganese oxides do not dissolve under high $\mathrm{pH}$ conditions caused by the sprayed calcium hydroxide and are not expensive.

In this paper, at first we studied lead removal from a high $\mathrm{pH} 12.4$ aqueous solution using mesoporous manganese oxide as an adsorbent. Then, the lead species adsorbed under high $\mathrm{pH}$ of 12.4 on various oxides was analyzed especially with X-ray absorption spectroscopy.

\section{Experimental}

\subsection{Preparation of Mesoporous Manganese Oxide}

Into $50 \mathrm{~mL}$ of distilled water, $10 \mathrm{mmol}$ of potassium permanganate was dissolved. Then, $3.3 \mathrm{mmol}$ of maleic acid in $50 \mathrm{~mL}$ of distilled water was added as a reducing agent and the mixture was stirred for $1 \mathrm{~h}$. After aging for $24 \mathrm{~h}$ at room temperature, the resulting black precipitate was washed with distilled water. After drying at $70^{\circ} \mathrm{C}$ overnight, the mesoporous manganese oxide (Meso-Mn) was obtained by calcination in air at $300^{\circ} \mathrm{C}$ for $2 \mathrm{~h}$.

For comparison, $\mathrm{SiO}_{2}$ (Q-10; Fuji Silysia Chemical Ltd., Japan), $\mathrm{Al}_{2} \mathrm{O}_{3}$ (KHD-24; Sumitomo Chemical Co. Ltd., Japan), and $\mathrm{ZrO}_{2}$ (JRC-ZRO-5; Catalysis Society of Japan) were also used to remove lead.

\subsection{Removal of Lead from $\mathrm{pH} 12.4$ Aqueous Solution}

\subsubsection{Preparation of Lead Solution of pH 12.4}

Into $1000 \mathrm{~mL}$ of distilled water, $2.02 \mathrm{~g}(27.3 \mathrm{mmol})$ of $\mathrm{Ca}(\mathrm{OH})_{2}$ was added. The container was sealed so that no $\mathrm{CO}_{2}$ dissolved into the alkaline solution. The content was agitated for $1 \mathrm{~h}$ in order to saturate $\mathrm{Ca}(\mathrm{OH})_{2}$ and stood still at room temperature for $3 \mathrm{~d}$. By filtration, a solution saturated with $\mathrm{Ca}(\mathrm{OH})_{2}$ was ob- 
tained. The $\mathrm{pH}$ of this solution was measured with a $\mathrm{pH}$ meter to be 12.4. Into this solution, $0.16-1.28 \mathrm{~g}(0.48-3.84 \mathrm{mmol})$ of $\mathrm{Pb}\left(\mathrm{NO}_{3}\right)_{2}$ was dissolved. Thus, a solution containing a desired concentration of lead at $\mathrm{pH} 12.4$ was prepared.

\subsubsection{Removal of Lead}

Typically, into $100 \mathrm{~mL}$ of the prepared lead solution, a $0.20 \mathrm{~g}$ portion of Meso-Mn was added, and the mixture was stirred with a Teflon-coated stirrer bar for $1 \mathrm{~min}$ to $240 \mathrm{~h}$ at room temperature. The removal was carried out in a sealed glass Erlenmeyer flask, preventing dissolution of $\mathrm{CO}_{2}$ into the alkaline solution. After adsorption of lead, Meso-Mn was centrifuged and the concentrations of lead and calcium species in the supernatant were analyzed with Inductively Coupled Plasma (ICP) spectroscopy (ICPS-7510, Shimadzu Corp., Japan). When the influence of co-existing calcium was investigated, $\mathrm{NaOH}$ was used instead of $\mathrm{Ca}(\mathrm{OH})_{2}$ to control $\mathrm{pH}$.

\subsection{Characterization}

The powder X-ray diffraction (XRD) patterns were obtained with RMT-18kWHFVE (Rigaku, Japan) with $\mathrm{Cu} \mathrm{K} \alpha$-radiation at $40 \mathrm{kV}$ and $20 \mathrm{~mA} . \mathrm{N}_{2}$ adsorption-desorption isotherms were obtained with BELSORP-mini2 (MicrotracBEL, Japan), and the pore size distribution (BJH method) and BET surface area were calculated based on the adsorption-desorption isotherms. The elemental analysis was carried out using ICP. The analysis sample was prepared by dissolving 0.050 $\mathrm{g}$ of a solid before or after removal of lead in $20 \mathrm{~mL}$ of $10 \mathrm{~mol} \cdot \mathrm{L}^{-1} \mathrm{HNO}_{3}$ with a few drops of $30 \mathrm{wt} \% \mathrm{H}_{2} \mathrm{O}_{2}$ aqueous solution. Before measurement, the solution was diluted to a desired concentration range.

The zeta potential was measured by the laser Doppler method with Zetasizer Nano-Z (ZEN2600, Malvern Instruments Inc., United Kingdom). For the measurement, $0.020 \mathrm{~g}$ of powder sample was dispersed in distilled water. The $\mathrm{pH}$ of the suspension was arranged with aqueous $\mathrm{HCl}, \mathrm{NaOH}$ or $\mathrm{Ca}(\mathrm{OH})_{2}$ solution. X-ray photoelectron spectra (XPS) were recorded by JEOL JPS-9000MX (JEOL, JAPAN) with $\mathrm{Mg} \mathrm{K} \alpha$-radiation at $10 \mathrm{kV}$ and $10 \mathrm{~mA}$, and the peak position was calibrated with $\mathrm{Pt}_{4 \mathrm{fr} / 2}$ at $70.9 \mathrm{eV}$ as an internal standard.

$\mathrm{X}$-ray absorption fine structure (XAFS) and X-ray absorption near edge spectrum (XANES) were obtained at 14B2 beamline at SPring-8, Japan. Silicon (311) crystal was used as a monochromator. For the measurement of $\mathrm{Pb} \mathrm{L}_{\mathrm{III}}$ edge of high $\mathrm{Pb}$ concentration samples, the transmission mode was adopted. For the low concentration samples, $\mathrm{Pb} \mathrm{L}_{\mathrm{III}}$ edge spectra were collected by the fluorescence mode using 19-element Ge semi-conductivity detector. Radial structure function was Fourier transformed for the XAFS vibration between wave number $k$ of 2 and $8 \AA^{-1}$. Powder samples were pelletized together with boron nitride and solution samples were packed in polyethylene bag.

\section{Results and Discussion}

The preparation and characterization of mesoporous manganese oxide (Me- 
so-Mn) have been reported elsewhere [24] [26]. In brief, Meso-Mn was amorphous (XRD) and mesoporous (inter-particle mesopores of about $5 \mathrm{~nm}$ ) and had a high BET surface area of approximately $250 \mathrm{~m}^{2} \cdot \mathrm{g}^{-1}$.

\subsection{Removal of Lead at pH 12.4}

The adsorption isotherm was studied in order to understand the mechanism of adsorption and the maximum amount of adsorption. When lead adsorption was carried out at $\mathrm{pH} 12.4$ controlled with $\mathrm{NaOH}$, a Langmuir-type adsorption phenomenon was observed (Figure 1) with a monolayer adsorption capacity of lead

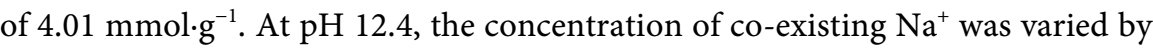
adding $\mathrm{NaNO}_{3}$, and the influence of the concentration of $\mathrm{Na}^{+}$is indicated in Figure 2. From these results, it can be said that the existence of $\mathrm{Na}^{+}$does not influence the adsorption of lead.

Figure 3 shows the adsorption isotherm for calcium. Calcium also indicated the Langmuir-type adsorption, and the monolayer adsorption capacity was calculated to be $2.97 \mathrm{mmol} \cdot \mathrm{g}^{-1}$. Then, adsorption of lead in the presence of $\mathrm{Ca}^{2+}$ was investigated (Figure 4). The adsorption behavior of lead could be analyzed again by the Langmuir-type equation. The analysis showed a monolayer adsorption capacity of $1.83 \mathrm{mmol} \cdot \mathrm{g}^{-1}$. In addition, lead and calcium seemed to compete for the same adsorption site because the total amount of adsorption was almost constant at ca. $3.2 \mathrm{mmol} \cdot \mathrm{g}^{-1}$. At saturation, the molar ratio of lead to calcium was close to unity, suggesting the formation of a specific complex.

To confirm the superiority of Meso-Mn, the removal of lead with $\mathrm{SiO}_{2}, \mathrm{Al}_{2} \mathrm{O}_{3}$ and $\mathrm{ZrO}_{2}$ was investigated. To make the comparison simple, oxides having surface areas similar to that of Meso-Mn were used. As shown in Figure 5, Meso-Mn

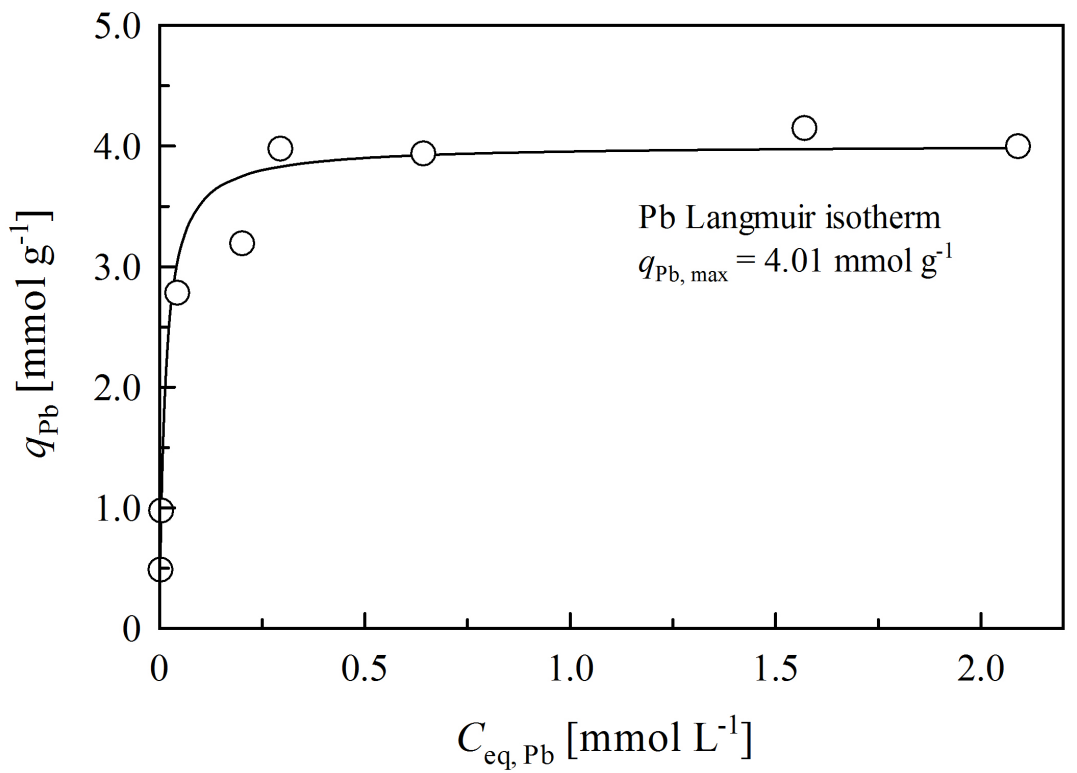

Figure 1. Adsorption isotherm of $\mathrm{Pb}$ with Meso-Mn under $\mathrm{pH}$ control with $\mathrm{NaOH}$. Adsorbent: $0.050 \mathrm{~g}$, Initial $\mathrm{Pb}$ concentration: 0 - $2.96 \mathrm{mmol} \cdot \mathrm{L}^{-1}$, Initial $\mathrm{Na}$ concentration: $40.1 \mathrm{mmol} \cdot \mathrm{L}^{-1}$, Solution: $100 \mathrm{~mL}$, Initial $\mathrm{pH}$ : 12.4 , Time: $240 \mathrm{~h}$. 


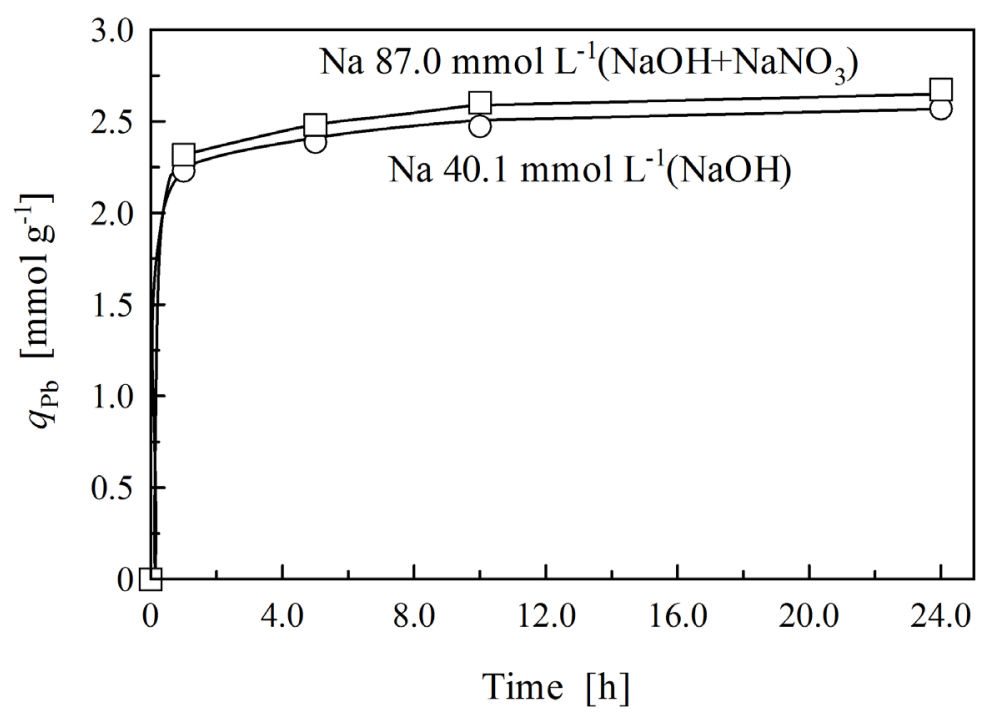

Figure 2. Influence of co-existence of $\mathrm{Na}$ on removal of $\mathrm{Pb}$ with Meso-Mn. Adsorbent: $0.050 \mathrm{~g}$, Initial $\mathrm{Pb}$ concentration: $2.89 \mathrm{mmol} \cdot \mathrm{L}^{-1}$, Initial $\mathrm{Na}$ concentration: $40.1 \mathrm{mmol}$ or $87.0 \mathrm{mmol} \cdot \mathrm{L}^{-1}$, Solution: $100 \mathrm{~mL}$, Initial $\mathrm{pH}$ : 12.4, $\mathrm{pH}$ control: $\mathrm{NaOH}$, Time: 0 - $24 \mathrm{~h}$.

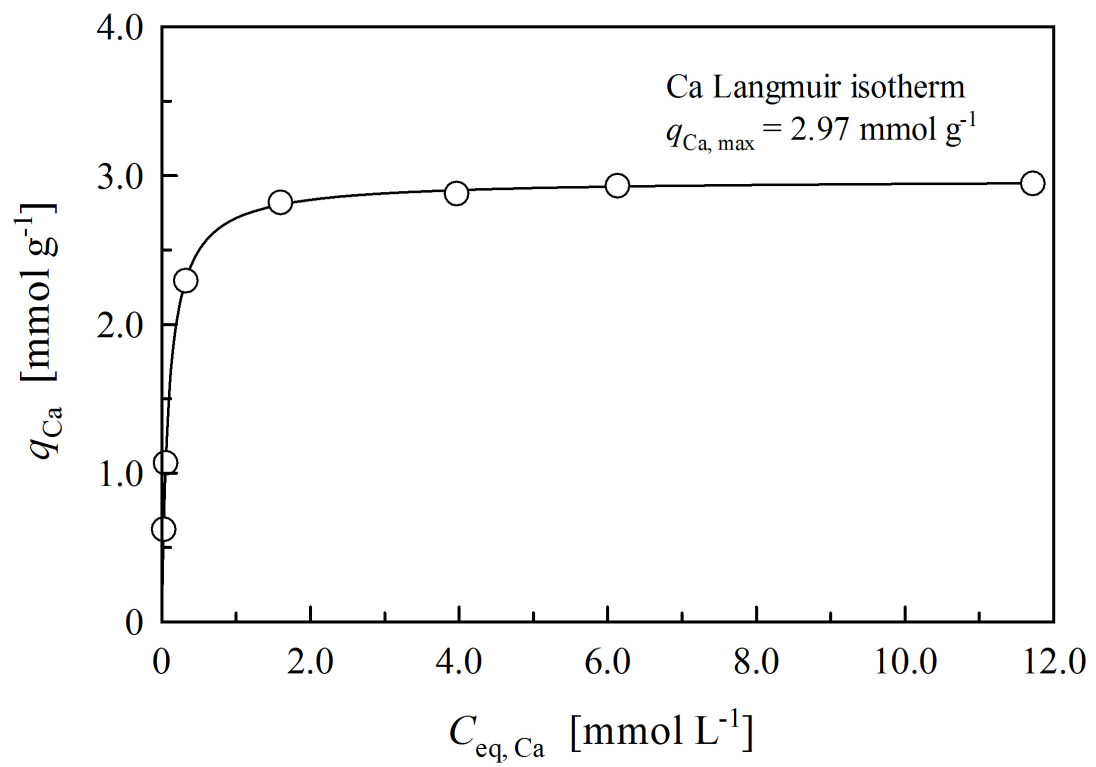

Figure 3. Adsorption isotherm of Ca with Meso-Mn. Adsorbent: $0.20 \mathrm{~g}$, Initial Ca concentration: 0 - $19.2 \mathrm{mmol} \cdot \mathrm{L}^{-1}$, Solution: $100 \mathrm{~mL}$, Initial pH: 12.4, $\mathrm{pH}$ control: $\mathrm{NaOH}$, Time: $240 \mathrm{~h}$.

and $\mathrm{SiO}_{2}$ removed lead most. As $\mathrm{SiO}_{2}$ also adsorbed a large amount of $\mathrm{Ca}^{2+}$, Meso-Mn was the most selective for the lead removal. In addition, the dissolution of $\mathrm{SiO}_{2}$ and $\mathrm{Al}_{2} \mathrm{O}_{3}$ themselves was confirmed for $\mathrm{SiO}_{2}$ and $\mathrm{Al}_{2} \mathrm{O}_{3}$. Thus, Meso-Mn was the best choice for the removal of lead at a high $\mathrm{pH}$ of 12 .

In summary for the adsorption of lead from the high $\mathrm{pH}$ solution, manganese oxide was the most promising adsorbent. The Langmuir-type adsorption was observed for both lead and calcium. Lead and calcium competed for the same adsorption site. It was suggested that lead and calcium formed a specific complex on Meso-Mn. 


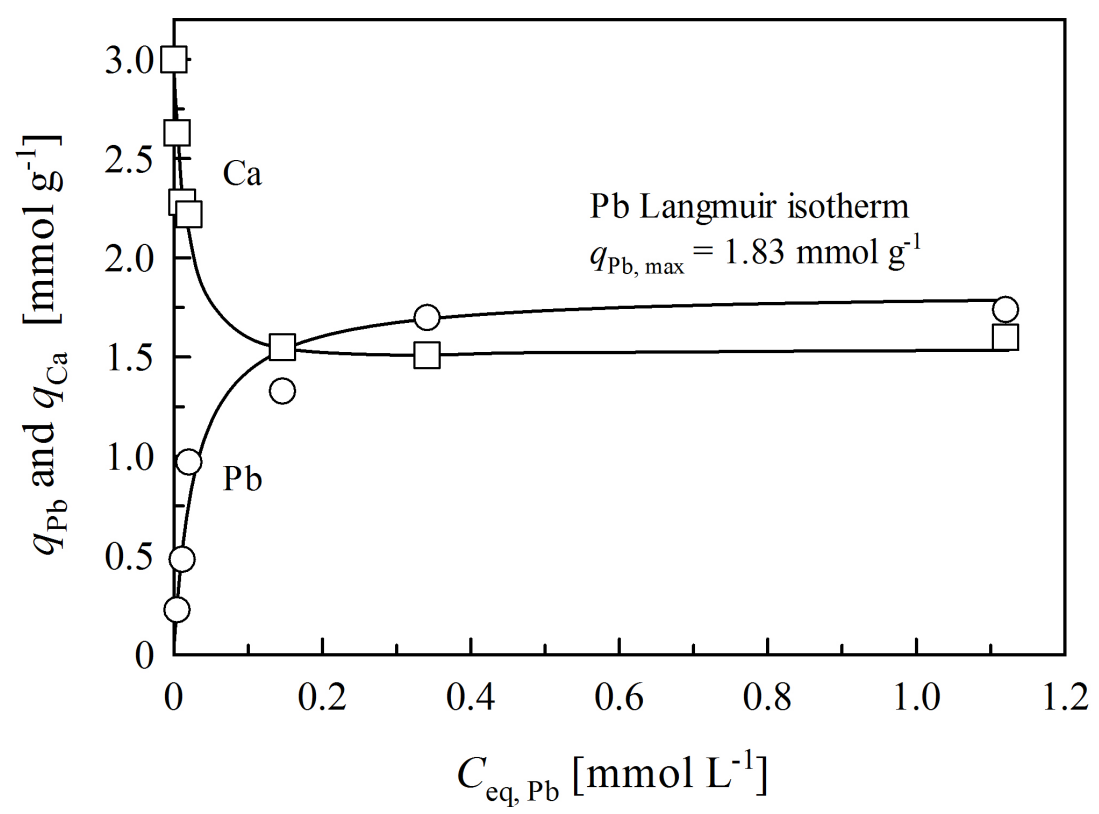

Figure 4. Adsorption isotherms of $\mathrm{Pb}$ and $\mathrm{Ca}$ with Meso-Mn. Adsorbent: $0.20 \mathrm{~g}$, Initial $\mathrm{Pb}$ concentration: 0 - $3.86 \mathrm{mmol} \cdot \mathrm{L}^{-1}$, Initial Ca concentration: $19.2 \mathrm{mmol} \cdot \mathrm{L}^{-1}$, Solution: $100 \mathrm{~mL}$, Initial pH: 12.4, pH control: $\mathrm{Ca}(\mathrm{OH})_{2}$, Time: $240 \mathrm{~h}$.

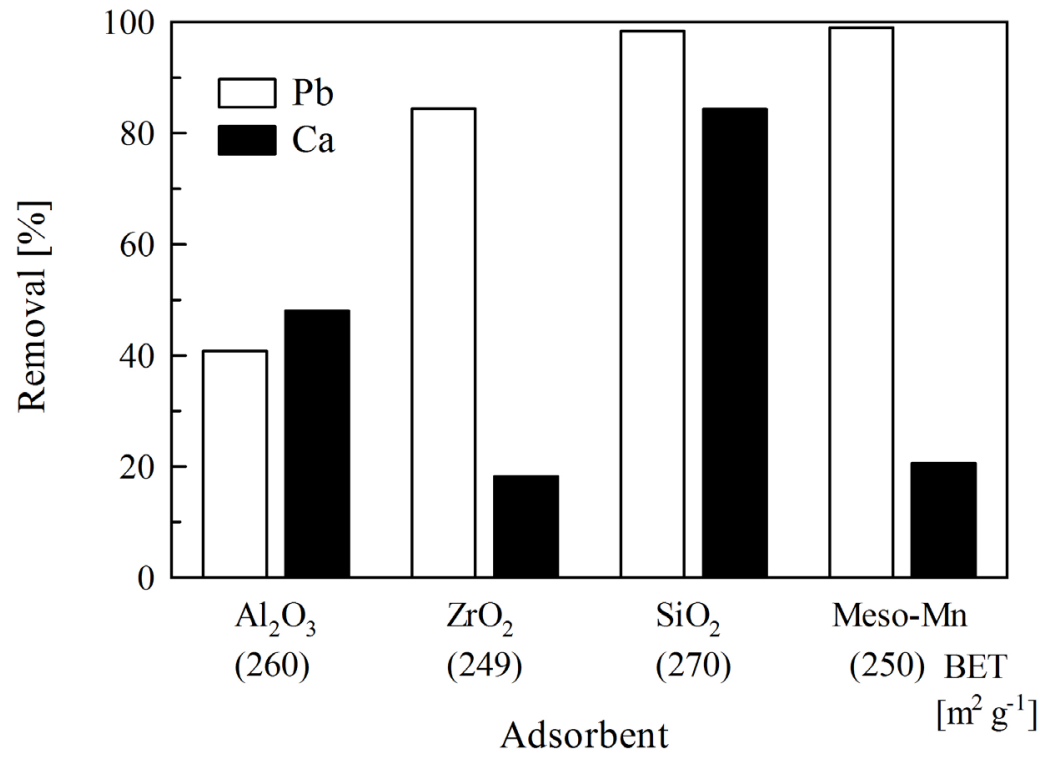

Figure 5. Removal of $\mathrm{Pb}$ and $\mathrm{Ca}$ with various metal oxides. Adsorbent: $0.20 \mathrm{~g}$, Initial $\mathrm{Pb}$ concentration: $1.92 \mathrm{mmol} \cdot \mathrm{L}^{-1}$, Initial Ca concentration: $19.2 \mathrm{mmol} \cdot \mathrm{L}^{-1}$, Solution: $100 \mathrm{~mL}$, Initial pH: $12.4, \mathrm{pH}$ control: $\mathrm{Ca}(\mathrm{OH})_{2}$, Time: $240 \mathrm{~h}$.

\subsection{X-Ray Absorption Spectroscopy}

\subsubsection{Lead Species in the Solution}

The same XANES spectra, and therefore the same radial structure function, were observed for the lead species in solution between $\mathrm{pH} 4$ and 10.5 (Figure 6). However, different XANES and XAFS spectra were observed at $\mathrm{pH} 12.4$ (Figure 7). Up to $\mathrm{pH} 10.5$, it is suggested from the coefficient of complex formation [27] 


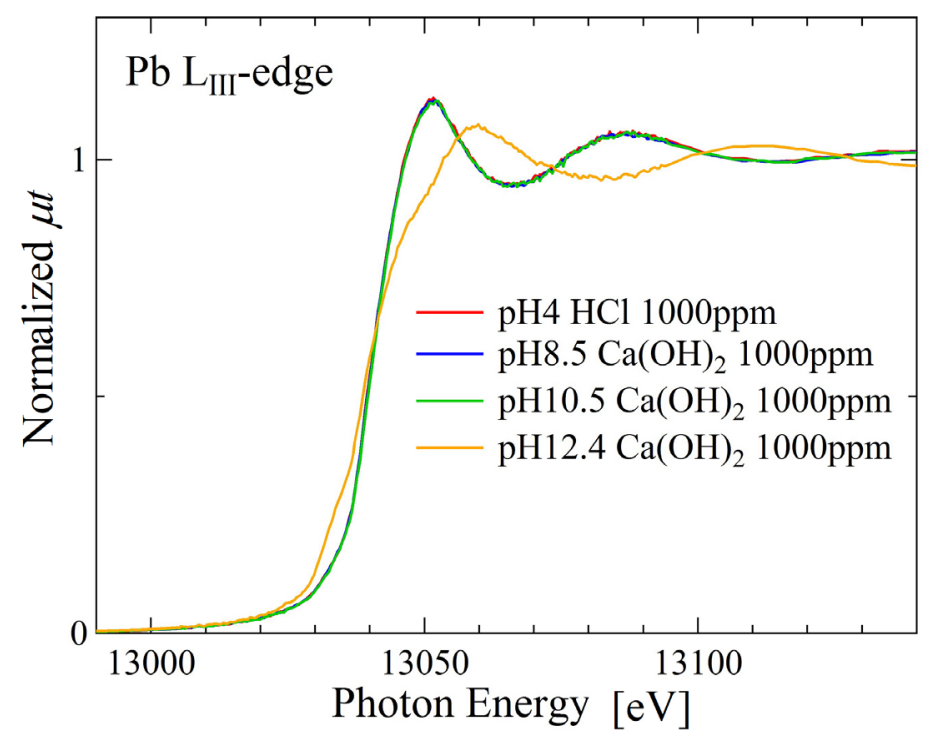

Figure 6. XANES spectra of lead species in the solution of various $\mathrm{pH}$ controlled with $\mathrm{Ca}(\mathrm{OH})_{2}$. Pb concentration: $1000 \mathrm{ppm}$.

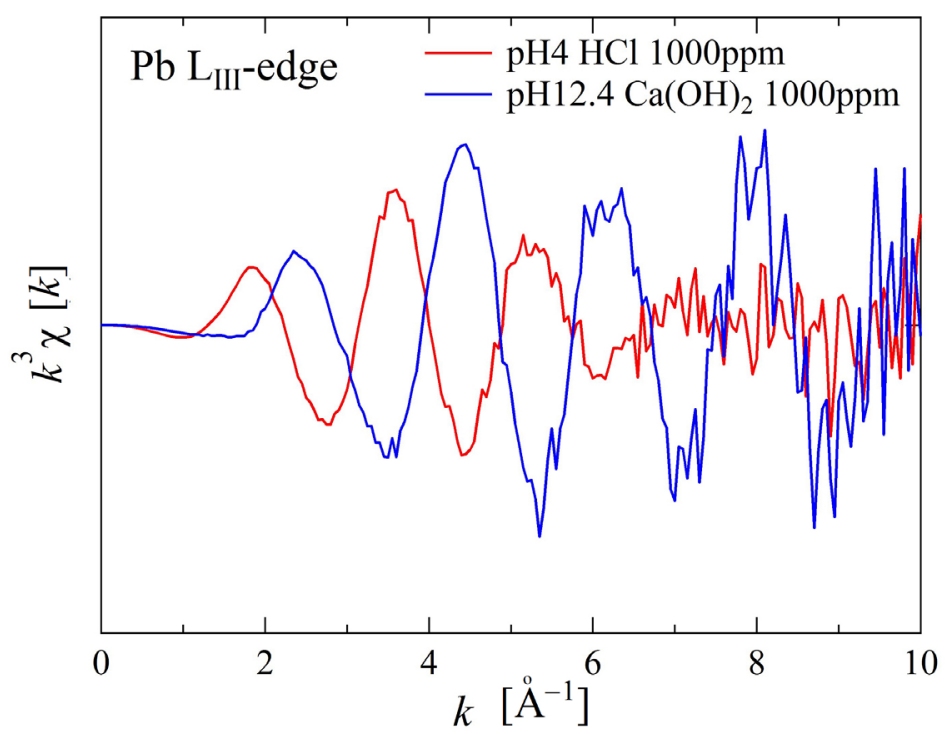

Figure 7. EXAFS vibration spectra for lead species in the solution at $\mathrm{pH} 4$ and $\mathrm{pH}$ 12.4. $\mathrm{Pb}$ concentration: $1000 \mathrm{ppm}$.

that lead exists as $\mathrm{Pb}^{2+}, \mathrm{Pb}(\mathrm{OH})^{+}$and $\mathrm{Pb}(\mathrm{OH})_{2}$ (Electronic supplementary information Figure $\mathrm{S} 1)$. On the other hand, $\mathrm{Pb}(\mathrm{OH})_{3}^{-}$is suggested at $\mathrm{pH}$ 12.4. Thus, it was revealed that when lead existed as cationic or neutral species, the structure of the first coordination sphere was the same. This is the first XANES information reported for lead in alkaline media.

For the XANES spectra at $\mathrm{pH} 12.4$, different spectra were obtained when $\mathrm{Ca}(\mathrm{OH})_{2}$ and $\mathrm{NaOH}$ were used as the $\mathrm{pH}$ controller (Figure 8). This may be because $\mathrm{Ca}(\mathrm{OH})^{+}$in the $\mathrm{Ca}(\mathrm{OH})_{2}$ solution (Electronic supplementary information Figure S2) could have Coulomb interaction with $\mathrm{Pb}(\mathrm{OH})_{3}^{-}$while in $\mathrm{NaOH}$ solution this kind of interaction did not occur. 


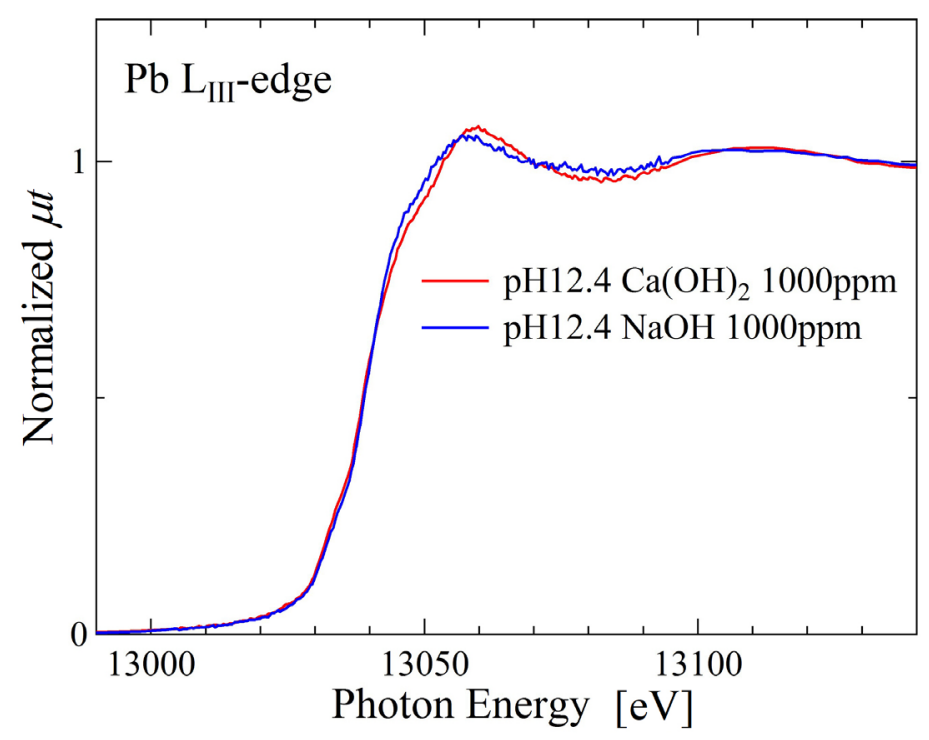

Figure 8. XANES spectra for lead species in the solution at $\mathrm{pH} 12.4$ controlled with $\mathrm{Ca}(\mathrm{OH})_{2}$ or $\mathrm{NaOH}$. Pb concentration: 1000 ppm.

\subsubsection{Lead Species Adsorbed on Oxides}

When the concentration of lead was $3000 \mathrm{ppm}$ in the presence of $\mathrm{Ca}(\mathrm{OH})_{2}$, the highest concentration in the experiment, the solution was not transparent and a white suspension was observed. The distance from lead to the first coordination sphere oxygen in the suspension (Figure 9) coincided with those for lead species adsorbed on oxides, Meso- $\mathrm{Mn}\left(\mathrm{MnO}_{2}\right), \mathrm{SiO}_{2}, \mathrm{Al}_{2} \mathrm{O}_{3}$ and $\mathrm{ZrO}_{2}$ (Figure 10), suggesting that the same lead species was adsorbed on each oxide. Furthermore, the same XANES spectra were obtained for different amount of lead adsorbed on oxides, suggesting that the structure of adsorbed species does not depend on the amount of lead adsorbed on oxides.

As in Figure 5, depending on the adsorbents, the amounts of lead and calcium adsorbed on oxides were different, meaning different cation selectivity. On Meso- $\mathrm{Mn}$ and $\mathrm{ZrO}_{2}$, the molar ratio of $\mathrm{Pb}$ to $\mathrm{Ca}$ was about unity. On the other hand, a few times more $\mathrm{Ca}$ than $\mathrm{Pb}$ adsorbed on $\mathrm{Al}_{2} \mathrm{O}_{3}$ and $\mathrm{SiO}_{2}$. The dissolution of $\mathrm{Al}_{2} \mathrm{O}_{3}$ and $\mathrm{SiO}_{2}$ surface was observed vide supra under highly alkaline solution of $\mathrm{pH} 12.4$, and dissolved aluminic acid or silicic acid might have formed calcium aluminate or calcium silicate on $\mathrm{Al}_{2} \mathrm{O}_{3}$ and $\mathrm{SiO}_{2}$, respectively. In the radial structure function for $\mathrm{Al}_{2} \mathrm{O}_{3}$ and $\mathrm{SiO}_{2}$ (Figure 10), small peaks could be noticed in the second or third coordination sphere and this is different from the phenomenon for $\mathrm{MnO}_{2}$ which does not dissolve in the highly alkaline conditions.

Thus, the behavior of lead in the highly alkaline conditions was analyzed for the first time and this information is very important to develop excellent materials to remove lead in water.

\subsection{Adsorbed Species}

First, the species of lead and calcium in the solution at different $\mathrm{pH}$ were estimated by the coefficient of complex formation [27] (Electronic supplementary 


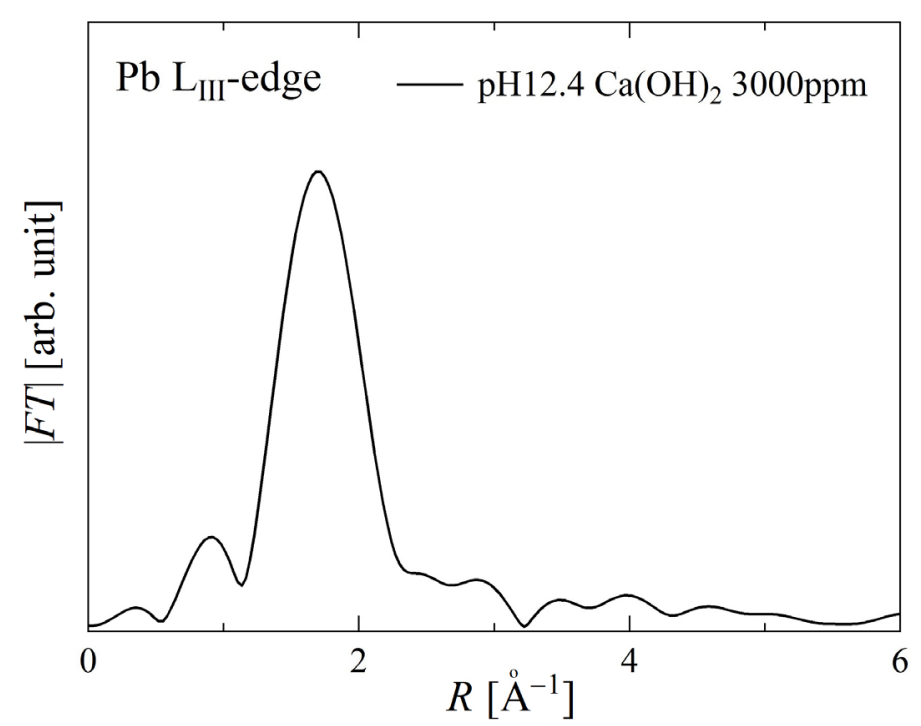

Figure 9. Radial structure function for high concentration lead suspension at $\mathrm{pH} 12.4$ controlled with $\mathrm{Ca}(\mathrm{OH})_{2}$. $\mathrm{Pb}$ concentration: $3000 \mathrm{ppm}$.

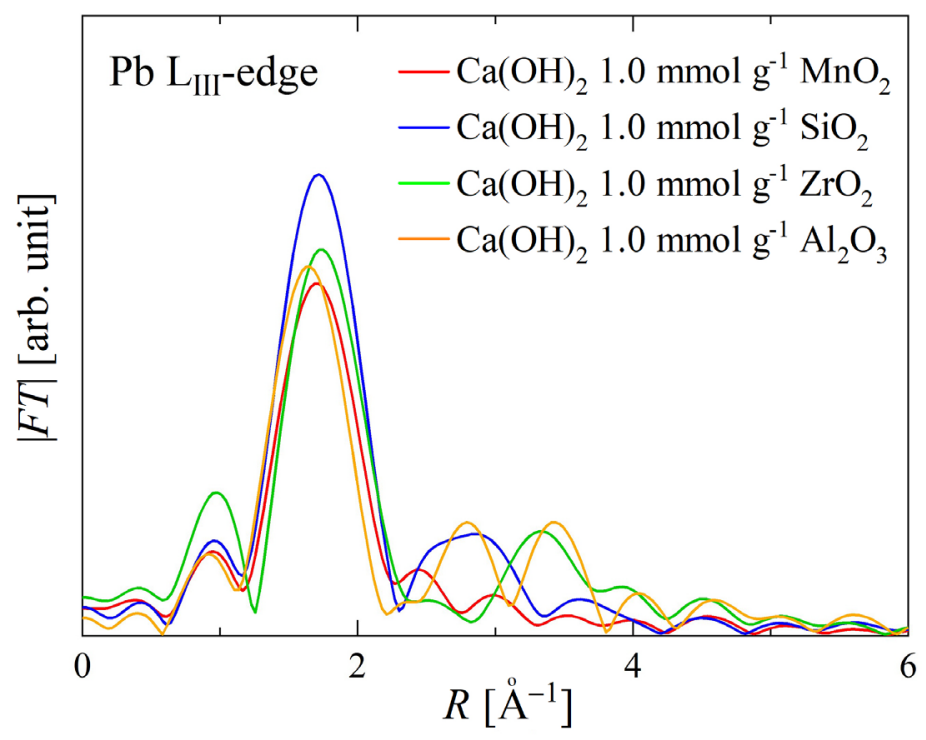

Figure 10. Radial structure function of lead species adsorbed on various oxides. Initial pH: $12.4, \mathrm{pH}$ control: $\mathrm{Ca}(\mathrm{OH})_{2}, \mathrm{~Pb}: 1.0 \mathrm{mmol} \cdot \mathrm{g}^{-1}$.

information Figure S1, Figure S2). As mentioned in 3.2.1, lead exists as $\mathrm{Pb}^{2+}$, $\mathrm{Pb}(\mathrm{OH})^{+}, \mathrm{Pb}(\mathrm{OH})_{2}$, and $\mathrm{Pb}(\mathrm{OH})_{3}^{-}$, and the main lead species at $\mathrm{pH} 12.4$ is estimated to be $\mathrm{Pb}(\mathrm{OH})_{3}^{-}$. Similarly, calcium exists as $\mathrm{Ca}^{2+}$ and $\mathrm{Ca}(\mathrm{OH})^{+}$, and both species may exist almost equally at $\mathrm{pH}$ 12.4. It is important that both anionic $\mathrm{Pb}(\mathrm{OH})_{3}^{-}$and cationic $\mathrm{Ca}(\mathrm{OH})^{+}$exist at $\mathrm{pH} 12.4$.

The zeta potential of Meso-Mn at $\mathrm{pH} 12.4$ was ca. $-30 \mathrm{mV}$, when $\mathrm{pH}$ was controlled with $\mathrm{NaOH}$. On the other hand, when the zeta potential was measured at $\mathrm{pH} 12.4$ under $\mathrm{pH}$ control with $\mathrm{Ca}(\mathrm{OH})_{2}$, the zeta potential was ca. +20 $\mathrm{mV}$. Considering the fact that the co-existence of $\mathrm{Na}^{+}$had no influence on the adsorption of lead (vide supra), $\mathrm{Na}^{+}$did not adsorb on Meso-Mn. In contrast, 
calcium species were adsorbed on Meso-Mn, and the charge on Meso-Mn became positive. Thus, the adsorption of lead species on Meso-Mn at pH 12.4 controlled with $\mathrm{Ca}(\mathrm{OH})_{2}$ may be by an electrostatic interaction between negative species, $\mathrm{Pb}(\mathrm{OH})_{3}^{-}$, and a positive surface bearing $\mathrm{Ca}(\mathrm{OH})^{+}$. This is in accordance with the results by XANES in Figure 8.

To directly investigate the adsorbed lead species, Meso-Mn was dried at $80^{\circ} \mathrm{C}$ overnight after the adsorption of lead, and analyzed with XRD. No distinct diffraction pattern related to lead species could be observed, even though the amount of lead was sufficiently high to be detected with XRD (data not shown). This may be because the lead species existed in the form of a monolayer. Even if lead existed as $\mathrm{Pb}(\mathrm{OH})_{2}$, the stability of $\mathrm{Pb}(\mathrm{OH})_{2}$ has been questioned [28], and observing the diffraction pattern of $\mathrm{Pb}(\mathrm{OH})_{2}$ may be difficult.

The valence state of lead was studied with XPS of $\mathrm{Pb} 4 \mathrm{f}_{7 / 2}$ (Figure 11) and the valence of lead was 2+. XPS of the commercial reagent $\mathrm{PbO}$ showed its peak at $137.4 \mathrm{eV}$. From the binding energy, lead might have adsorbed as $\mathrm{PbO}$. However, as mentioned above, it is known that $\mathrm{Pb}(\mathrm{OH})_{2}$ is unstable [28], and therefore the possibility cannot be excluded that $\mathrm{Pb}(\mathrm{OH})_{2}$ or $\mathrm{Pb}(\mathrm{OH})_{3}^{-}$changed to $\mathrm{PbO}$ during the drying process.

Some researchers reported the adsorption of hydrated $\mathrm{Pb}$ species or other divalent cations such as $\mathrm{Ni}^{2+}$ and $\mathrm{Ca}^{2+}$ on a variety of adsorbents using EXAFS [29] [30] [31]. Under neutral conditions, adsorption of hydrated $\mathrm{Pb}^{2+}$ is estimated [29] [30]. Bargar et al. reported that hydrated lead lost some of hydrated water on adsorption [29]. As far as we know, there are no reports by EXAFS on the adsorbed lead species under high $\mathrm{pH}$ conditions.

As discussed above, we do not have any decisive idea for the adsorbed lead species at this moment. However, considering the equimolar adsorption of lead and calcium, the existence of $\mathrm{Pb}-\mathrm{O}$ bond and the valence of lead to be $2+$, we

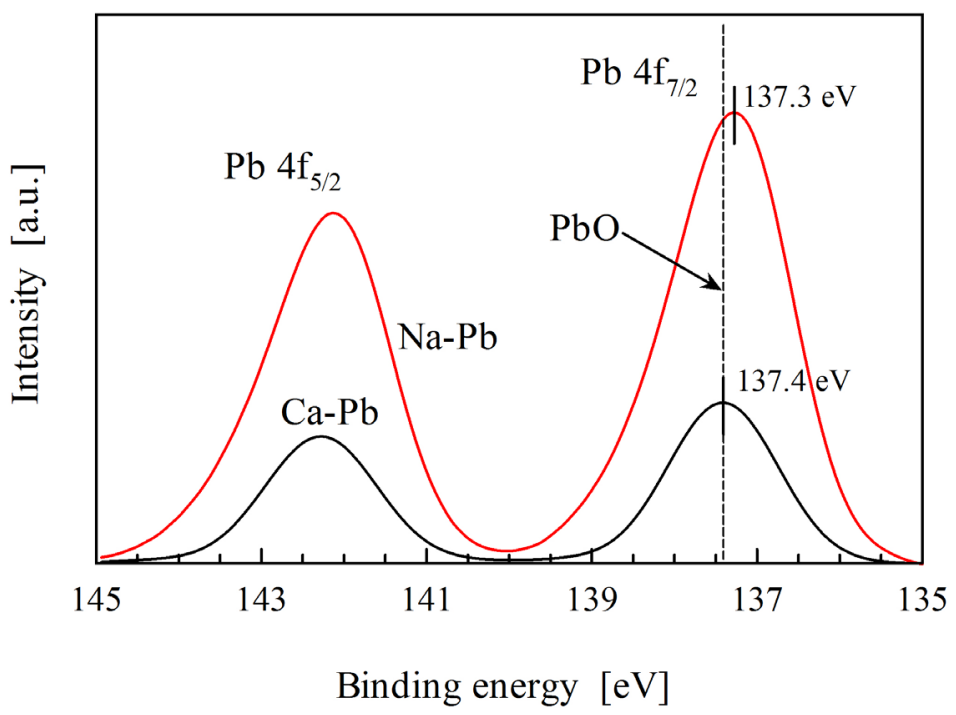

Figure 11. XPS spectra for $\mathrm{Pb} 4 \mathrm{f}$ adsorbed on Meso-Mn. $\mathrm{pH}$ control: $\mathrm{Ca}(\mathrm{OH})_{2}$ for $\mathrm{Ca}-\mathrm{Pb}$ and $\mathrm{NaOH}$ for $\mathrm{Na}-\mathrm{Pb}$. 
may hypothesize the existence of a double hydroxide composed of lead and calcium of a probable formula of $\mathrm{CaPb}(\mathrm{OH})_{4}$.

\section{Conclusions}

Lead adsorption on oxides from a high $\mathrm{pH}$ aqueous solution was studied and manganese oxide was the most promising adsorbent. It was suggested that lead and calcium species competed for the same adsorption site on manganese oxide and the amount of removed lead reached $1.8 \mathrm{mmol} \cdot \mathrm{g}^{-1}$ under the co-existence of calcium hydroxide. The structure of lead species in the solution was different at $\mathrm{pH} 12.4$ and at $\mathrm{pH}$ lower than 10.5. The adsorbed lead species was not made clear; however, a double hydroxide composed of lead and calcium like $\mathrm{CaPb}(\mathrm{OH})_{4}$ was estimated. This information is very important to develop materials to remove lead in high $\mathrm{pH}$ water from the buried waste.

Based on the knowledge obtained, more promising material would be prepared by a monolayer loading of manganese oxide on a support of higher surface area than about $300 \mathrm{~m}^{2} \cdot \mathrm{g}^{-1}$.

\section{Acknowledgements}

Part of the research was financially supported by "Strategic Project to Support the Formation of Research Bases at Private Universities": Matching Fund Subsidy from Ministry of Education, Culture, Sports, Science and Technology, 2012-2016. The synchrotron radiation experiments were performed at BL14B2 in the SPring-8 with the approval of the Japan Synchrotron Radiation Research Institute (JASRI) (Proposal No. 2015B1634). Part of the research was also financially supported by the Kansai University Fund for Domestic and Overseas Research Fund, 2018 and by the Kansai University Fund for the Promotion and Enhancement of Education and Research, 2019.

\section{Conflicts of Interest}

The authors declare no conflicts of interest regarding the publication of this paper.

\section{References}

[1] Nowak, B., Pessl, A., Aschenbrenner, P., Szentannai, P., Mattenberger, H., Rechberger, H., Hermann, L. and Winter, F. (2010) Heavy Metal Removal from Municipal Solid Waste Fly Ash by Chlorination and Thermal Treatment. Journal of Hazardous Materials, 179, 323-331. https://doi.org/10.1016/j.jhazmat.2010.03.008

[2] Wang, L., Jin, Y. and Nie, Y. (2010) Investigation of Accelerated and Natural Carbonation of MSWI Fly Ash with a High Content of Ca. Journal of Hazardous Materials, 174, 334-343. https://doi.org/10.1016/j.jhazmat.2009.09.055

[3] Karin, K.F., Christian, E., Gunnar, S. and Britt-Marie, S. (2010) Removal of Hazardous Metals from MSW Fly Ash-An Evaluation of Ash Leaching Methods. Journal of Hazardous Materials, 173, 310-317. https://doi.org/10.1016/j.jhazmat.2009.08.094 
[4] Olli, D., Hannu, N., Risto, P. and Gary, W. (2009) Comparison of the Characteristics of Bottom Ash and Fly Ash from a Medium-Size (32 MW) Municipal District Heating Plant Incinerating Forest Residues and Peat in a Fluidized-Bed Boiler. Fuel Processing Technology, 90, 871-878. https://doi.org/10.1016/j.fuproc.2009.04.013

[5] Kamikita, M. (2005) Haikibutsu Shori Houhou. JP2005-3683025.

[6] Pena, M., Meng, X., Korfiatis, G.P. and Jing, C. (2006) Adsorption Mechanism of Arsenic on Nanocrystalline Titanium Dioxide. Environmental Science \& Technology, 40, 1257-1262. https://doi.org/10.1021/es052040e

[7] Wijnja, H. and Schulthessy, C.P. (2000) Vibrational Spectroscopy Study of Selenate and Sulfate Adsorption Mechanisms on Fe and $\mathrm{Al}$ (Hydr)oxide Surfaces. Journal of Colloid and Interface Science, 229, 286-297. https://doi.org/10.1006/jcis.2000.6960

[8] Mustafa, S., Shahida, P., Naeem, A., Dilara, B. and Rehana, N. (2002) Sorption Studies of Divalent Metal Ions on ZnO. Langmuir, 18, 2254-2259. https://doi.org/10.1021/la0014149

[9] Criscenti, L.J. and Sverjensky, D.A. (2002) A Single-Site Model for Divalent Transition and Heavy Metal Adsorption over a Range of Metal Concentrations. Journal of Colloid and Interface Science, 253, 329-352. https://doi.org/10.1006/jcis.2002.8529

[10] Shakhapure, J., Vijayanand, H., Basavaraja, S. and Hiremath, V. (2005) Uses of $\alpha-\mathrm{Fe}_{2} \mathrm{O}_{3}$ and Fly Ash as Solid Adsorbents. Bulletin of Materials Science, 28, 713-718. https://doi.org/10.1007/BF02708542

[11] Lin, L.C., Thirumavalavan, M., Wang, Y.T. and Lee, J.F. (2010) Surface Area and Pore Size Tailoring of Mesoporous Silica Materials by Different Hydrothermal Treatments and Adsorption of Heavy Metal Ions. Colloids and Surfaces A: Physicochemical and Engineering Aspects, 369, 223-231. https://doi.org/10.1016/j.colsurfa.2010.08.032

[12] Thirumavalavan, M., Wang, Y.T., Lin, L.C. and Lee, J.F. (2011) Monitoring of the Structure of Mesoporous Silica Materials Tailored Using Different Organic Templates and Their Effect on the Adsorption of Heavy Metal Ions. The Journal of Physical Chemistry C, 115, 8165-8174. https://doi.org/10.1021/jp200029g

[13] Ma, Z., Ji, H., Teng, Y., Dong, G., Zhou, J., Tan, D. and Qiu, J. (2011) Engineering and Optimization of Nano- and Mesoporous Silica Fibers Using Sol-Gel and Electrospinning Techniques for Sorption of Heavy Metal Ions. Journal of Colloid and Interface Science, 358, 547-553. https://doi.org/10.1016/j.jcis.2011.02.066

[14] Xia, K., Ferguson, R.Z., Losier, M., Tchoukanova, N., Bruening, R. and Djaoued, Y. (2010) Synthesis of Hybrid Silica Materials with Tunable Pore Structures and Morphology and Their Application for Heavy Metal Removal from Drinking Water. Journal of Hazardous Materials, 183, 554-564. https://doi.org/10.1016/j.jhazmat.2010.07.060

[15] Stathi, P., Dimos, K., Karakassides, M.A. and Deligiannakis, Y. (2010) Mechanism of Heavy Metal Uptake by a Hybrid MCM-41 Material: Surface Complexation and EPR Spectroscopic Study. Journal of Colloid and Interface Science, 343, 374-380. https://doi.org/10.1016/j.jcis.2009.11.029

[16] Ma, T.Y., Zhang, X.J. and Yuan, Z.Y. (2009) High Selectivity for Metal Ion Adsorption: From Mesoporous Phosphonated Titanias to Meso-/Macroporous Titanium Phosphonates. Journal of Materials Science, 44, 6775-6785.

https://doi.org/10.1007/s10853-009-3576-7

[17] Showkat, A.M., Zhang, Y.P., Kim, M.S., Gopalan, A.I., Reddy, K.R. and Lee, K.P. (2007) Analysis of Heavy Metal Toxic Ions by Adsorption onto Amino-Functionalized Ordered Mesoporous Silica. Bulletin of the Korean Chemical Society, 28, 1985-1992. 
https://doi.org/10.5012/bkcs.2007.28.11.1985

[18] Zhang, L., Yu, C., Zhao, W., Hua, Z., Chen, H., Li, L. and Shi, J. (2007) Preparation of Multi-Amine-Grafted Mesoporous Silicas and Their Application to Heavy Metal Ions Adsorption. Journal of Non-Crystalline Solids, 353, 4055-4061. https://doi.org/10.1016/j.jnoncrysol.2007.06.018

[19] Sayari, A., Hamoudi, S. and Yang, Y. (2005) Applications of Pore-Expanded Mesoporous Silica. 1. Removal of Heavy Metal Cations and Organic Pollutants from Wastewater. Chemistry of Materials, 17, 212-216. https://doi.org/10.1021/cm048393e

[20] Liu, A.M., Hidajat, K., Kawi, S. and Zhao, D.Y. (2000) A New Class of Hybrid Mesoporous Materials with Functionalized Organic Monolayers for Selective Adsorption of Heavy Metal Ions. Chemical Communications, 230, 1145-1146. https://doi.org/10.1039/b0026611

[21] Brown, J., Richer, R. and Mercier, L. (2000) One-Step Synthesis of High Capacity Mesoporous $\mathrm{Hg}^{2+}$ Adsorbents by Non-Ionic Surfactant Assembly. Microporous and Mesoporous Materials, 37, 41-48. https://doi.org/10.1016/S1387-1811(99)00191-2

[22] Mercier, L. and Pinnavaia, T.J. (1997) Access in Mesoporous Materials: Advantages of a Uniform Pore Structure in the Design of a Heavy Metal Ion Adsorbent for Environmental Remediation. Advanced Materials, 9, 500-503.

https://doi.org/10.1002/adma.19970090611

[23] Jhon, Q.T., Averlant, R., Giraudon, J.M. and Lamonjer, J.F. (2010) Mesoporous Manganese Oxide Catalysts for Formaldehyde Removal: Influence of the Cerium Incorporation. Studies in Surface Science and Catalysis, 175, 517-520. https://doi.org/10.1016/S0167-2991(10)75098-9

[24] Hasegawa, Y., Fukumoto, K., Ishima, T., Yamamoto, H., Sano, M. and Miyake, T. (2009) Preparation of Copper-Containing Mesoporous Manganese Oxides and Their Catalytic Performance for CO Oxidation. Applied Catalysis B: Environmental, 89, 420-424. https://doi.org/10.1016/j.apcatb.2008.12.023

[25] Sinha, A.K., Suzuki, K., Takahara, M., Azuma, H., Nonaka, T. and Suzuki, N. (2008) Preparation and Characterization of Mesostructured $\gamma$-Manganese Oxide and Its Application to VOCs Elimination. The Journal of Physical Chemistry C, 112, 16028-16035. https://doi.org/10.1021/jp805211z

[26] Hong, X., Zhang, G., Zhu, Y. and Yang, H. (2003) Sol-Gel Synthesis and Characterization of Mesoporous Manganese Oxide. Materials Research Bulletin, 38, 1695-1703. https://doi.org/10.1016/j.materresbull.2003.07.005

[27] Kragten, J. (1978) Atlas of Metal-Ligand Equilibria in Aqueous Solution. Ellis Horwood Limited, Chichester, 534.

[28] Cheng, J., Zou, X., Meng, X., Yang, G., Lu, X., Wei, C., Sun, Z., Feng, H. and Yang, Y. (2010) Lead Hydroxide Nanowires Obtained from Lead Nitrate Solution by Adding Chloride Ions. Advanced Materials Research, 123-125, 719-722. https://doi.org/10.4028/www.scientific.net/AMR.123-125.719

[29] Bargar, J.R., Towle, S.N., Brown Jr., G.E. and Parks, G.A. (1996) Outer-Sphere $\mathrm{Pb}$ (II) Adsorbed at Specific Surface Sites on Single Crystal $\alpha$-Alumina. Geochimica et Cosmochimica Acta, 60, 3541-3547. https://doi.org/10.1016/0016-7037(96)00222-0

[30] Bargar, J.R., Towle, S.N., Brown Jr., G.E. and Parks, G.A. (1997) XAFS and Bond-Valence Determination of the Structures and Compositions of Surface Functional Groups and $\mathrm{Pb}(\mathrm{II})$ and $\mathrm{Co}(\mathrm{II})$ Sorption Products on Single-Crystal $\alpha$-Alumina. Journal of Colloid and Interface Science, 185, 473-492. 
https://doi.org/10.1006/jcis.1996.4574

[31] Trivedi, P. and Axe, L. (2001) Predicting Divalent Metal Sorption to Hydrous Al, Fe, and Mn Oxides. Environmental Science \& Technology, 35, 1779-1784. https://doi.org/10.1021/es001644+

\section{Electronic Supplementary Information (ESI)}

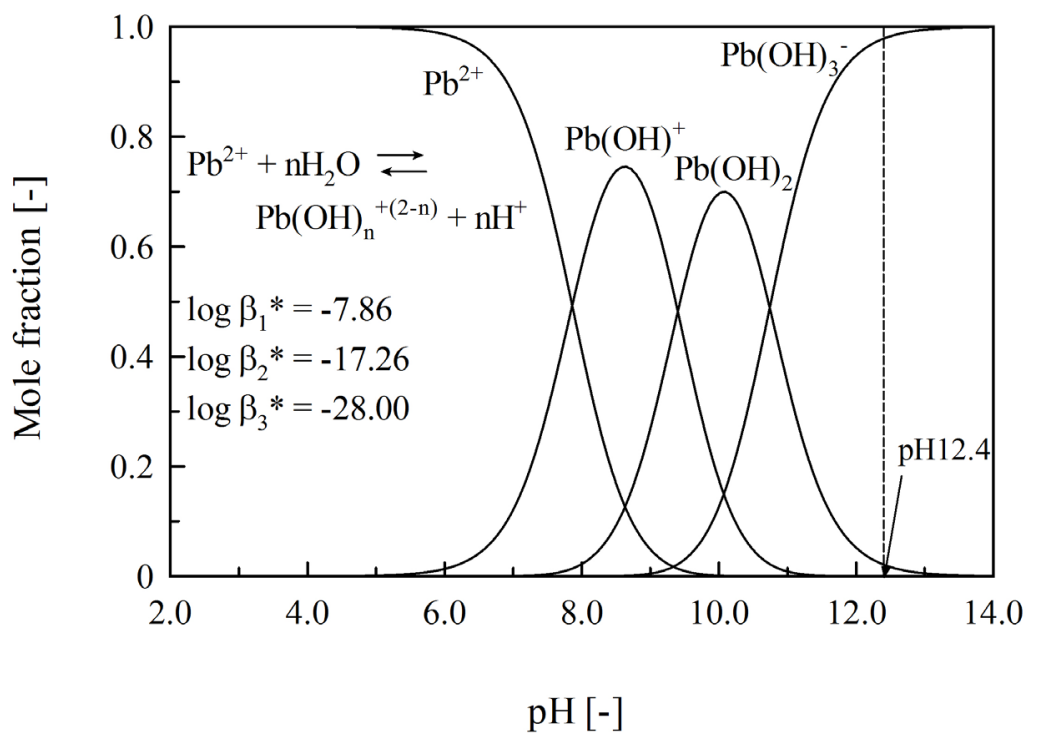

Figure S1. Calculated distribution diagram of $\mathrm{Pb}$ species in aqueous solution as a function of $\mathrm{pH}$.

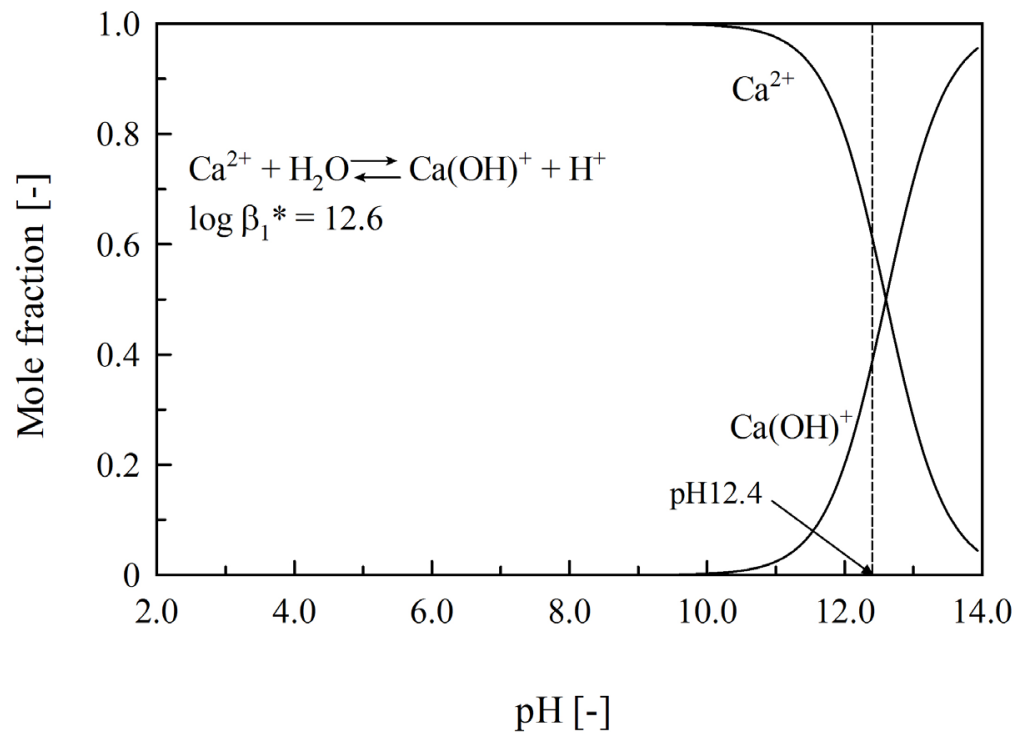

Figure S2. Calculated distribution diagram of $\mathrm{Ca}$ species in aqueous solution as a function of $\mathrm{pH}$. 